\title{
Photoreflectance and surface photovoltage spectroscopy characterisation of an InGaP/InGaAsN/GaAs NpN DHBT structure
}

\author{
Y.S. Huang, C.J. Lin, C.H. Wang, N.Y. Li, C.C. Fan and P.W. Li
}

\begin{abstract}
An InGaP/InGaAsN/GaAs NpN double-heterojunction bipolar transistor (DHBT) structure has been characterised using the techniques of photoreflectance (PR), including the dependence of the signals on the polarisation $\left\{\begin{array}{lll}1 & 1 & 0\end{array}\right]$ and $\left.\left[\begin{array}{lll}1 & 1 & 0\end{array}\right]\right\}$ of the incident radiation, and surface photovoltage spectroscopy (SPS). The ordering parameter of the InGaP is deduced from the polarisation dependence of the PR signals from the emitter region. The observed Franz-Keldysh oscillations have been used to evaluate the electric fields in the collector and emitter regions. The field in the collector region agrees well with the theoretical value, while the ficld in the emitter region is found to be about $25 \mathrm{kV} / \mathrm{cm}$ smaller than the theoretical value not taking into account the possible ordering-induced screening effect. The difference is ascribed to the influence of the piezoelectric field related to ordering. In addition, the InGaAsN band gap is determined to be $1.196 \mathrm{eV}$ by analysing the PR and SPS spectra in the base region. The narrower band gap of InGaAsN has led to a lower turn-on voltage, which shows great potential for the application of InGaAsN in low-power electronics.
\end{abstract}

\section{Introduction}

InGaAsN alloy systems are currently attracting significant attention owing to their potential application in optoelectronic devices [1-3]. Incorporation of a small amount of nitrogen $(\mathrm{N})$ into InGaAs results in a reduction of its lattice constant, thus reducing the strain in InGaAs layers grown on GaAs [1]. In addition, due to large band gap $\left(E_{\mathrm{g}}\right)$ bowing, $E_{\mathrm{g}}$ decreases as $\mathrm{N}$ is added [1]. The use of GaAs-lattice-matched InGaAsN could be a suitable approach to the realisation of low-power electronic devices. Progress in InGaAsN material quality has motivated the development of new heterojunction bipolar transistors (HBTs) using this alloy as the base to produce cost-effective low-power electronic devices for $\mathrm{GaAs}$ substrates. Recently a functional $\mathrm{NpN}$ InGaP/InGaAsN/ GaAs double heterojunction bipolar transistor (DHBT) has been reported [4]. Its initial performance was comparable with its conventional InGaP/GaAs counterpart and a reasonable reduction of $V_{\text {on }}(0.84 \mathrm{~V}$ instead of $0.97 \mathrm{~V})$ was observed, so that the potential application of InGaAsN in low-power electronics has been demonstrated.

\section{(1) IEE, 2003}

IEE Proceedings online no. 20030044

DOI: $10.1049 / \mathrm{ip}$-opt:20030044

Paper received 11 th November 2002

Y.S. Huang and C.J. Lin are with the Department of Electronic Engineering, National Taiwan University of Science and Technology, Taipei 106, Taiwan, Republic of China

C.H. Wang and N.Y. Li are with Kingmax Optoelectronics Inc., Hu Kou, Hsin Chu 303, Taiwan, Repubtic of China

C.C. Fan and P.W. Li are with the Department of Electrical Engincering, National Central University, Chung Li, Taoyuan 320. Taiwan, Republic of China

IEE Proc.-Optoelectron. Vol. 150, No. 1, February 2003
Photoreflectance (PR) [5] and surface photovoltage spectroscopy (SPS) [6] have proven to be valuable tools for the non-destructive room temperature characterisation of a number of device structures including HBTs, pseudomorphic high electron mobility transistors and quantum well lasers [7]. The sensitivity of PR to built-in electric fields has proven to be one of its most important properties for HBT characterisation. For sufficiently high electric fields the PR spectrum can display an oscillatory behaviour above the band gap, called Franz-Keldysh oscillations (FKOs). The period of these FKOs is a direct measure of the built-in electric field. For HBTs the PR technique has been used to evaluate the collector/base and emitter/base fields as well as alloy composition/or ordering parameter $[5,7]$. Mishori et al. recently demonstrated that SPS technique can be used to gain information about the base region [8]

We present a detailed PR and SPS investigation of an InGaP/InGaAsN/GaAs NpN DHBT structure fabricated by metal-organic chemical vapour deposition (MOCVD), including the dependence of the signals on polarisation $\left\{\begin{array}{lll}1 & 1 & 0\end{array}\right]$ and $\left[\begin{array}{lll}1 & 1 & 0\end{array}\right\}$ of the incident radiation. Under certain conditions InGaP has a strong tendency towards atomic ordering, which leads to a band gap reduction $\left(\triangle E_{B G R}\right)$, valence band splitting $\left(\Delta E_{V B S}\right)$ and related polarisation effects [9]. The observed FKOs have been used to evaluate the electric fields in the collector/base $\left(F^{\text {coll }}\right)$ and emitter/base $\left(F^{e m i t}\right)$ regions. These fields have been calculated based on a comprehensive, self-consistent model [10], including the photovoltaic effect. The difference between the experimentally measured field in the emitter/base region and that calculated from theory is discussed. In addition; the InGaAsN band gap is determined by analysing PR and SPS spectra from the base region. 


\section{Experimental}

The InGaP/InGaAsN/GaAs NpN DHBT structure used in this study was fabricated on undoped semi-insulating GaAs substrate by MOCVD. On top of the substrate was grown (a) a $5000 \AA \mathrm{n}^{+}-\mathrm{GaAs}$ subcollector layer followed by (b) a $5000 \AA \mathrm{n}^{-}$-GaAs collector layer, (c) a $700 \AA \mathrm{p}^{+}-$InGaAsN base layer, $(d)$ a $500 \AA \mathrm{n}$-lnGaP emitter layer, $(e)$ a $1000 \AA$ $\mathrm{n}^{+}$-GaAs emitter contact layer, and $(f)$ a $600 \AA \mathrm{n}^{+}-\mathrm{In}_{0-0.5}$ $\mathrm{Ga}_{1-0.5}$ As contact cap layer. The base layer was made of $\mathrm{p}^{+}-\mathrm{In}_{0.03} \mathrm{Ga}_{0.97} \mathrm{As}_{0.99} \mathrm{~N}_{0.01}$ with band gap $\sim 1.2 \mathrm{eV}$ which is lattice-matched to GaAs. $\delta$ doping was inserted in the emitter near the base-emitter (BE) junction to minimise the effect of the conduction band offset $\Delta E_{\mathrm{c}}$ on the value of $V_{\text {on }}$. In order to reduce the barrier between the basecollector (BC) junction, a $300 \AA$ strained $\operatorname{In}_{0-0.2} \mathrm{Ga}_{1-0.8} \mathrm{As}$ grading layer with $\delta$ doping in the collector near the $\mathrm{BC}$ junction was inserted to gradually increase the $E_{\mathrm{c}}$ from that of InGaAsN to that of GaAs. Trimethylindium, trimethylgallium, 100\% arsine $\left(\mathrm{AsH}_{3}\right)$ and 1,1-dimenthylhdrazine (DMHy) were used as the $\mathrm{In}, \mathrm{Ga}, \mathrm{As}$ and $\mathrm{N}$ precursors, respectively, for the growth of the InGaAsN base layer. The flow rate ratio of $\mathrm{DMHy} /\left(\mathrm{DMHy}+\mathrm{AsH}_{3}\right)$ was fixed at 0.95 . The compositions of indium and nitrogen were determined by secondary ion mass spectroscopy (SIMS) and high-resolution $\mathrm{X}$-ray diffraction measurements. The doping concentrations in the epilayers were confirmed with polaron and Hall measurements.

The PR modulation of the built-in electric field of the sample is caused by photoexcited electron-hole pairs created by an internally $\mathrm{AC}$ modulated $650 \mathrm{~nm}$ laser diode $\left(\sim 200 \mu \mathrm{W} / \mathrm{cm}^{2}\right)$ at $200 \mathrm{~Hz}$. The SPS measurement, which used normalised incident light intensity, was performed at normal incidence using a fixed grid and probe light chopped at $200 \mathrm{~Hz}$.

\section{Results and discussion}

The dashed lines in Fig. 1 show the $300 \mathrm{~K}$ PR spectra of the DHBT sample with optical electric-field vector $E \|\left[\begin{array}{lll}1 & 1 & 0\end{array}\right]$ and $E \|\left[\begin{array}{lll}1 & \overline{1} & 0\end{array}\right]$, respectively. The feature around $1.2 \mathrm{eV}$ is from the InGaAsN base region. Both the GaAs and $\mathrm{lnGaP}$ signals exhibit FKOs. The solid lines are lineshape fits [5] yielding InGaP band gaps of $1.845 \pm 0.002$ and $1.857 \pm 0.002 \mathrm{eV}$ for the two polarisations, as indicated by the arrows. This difference is due to the ordering in the InGaP material $[9,11]$. The ordering parameter $\eta$ can be estimated from either $\triangle E_{B G R}$ or $\Delta E_{V B S}$. Values of $\Delta E_{B G R}=70 \pm 2 \mathrm{meV}$ and $\Delta E_{V B S}=$ $13 \pm 2 \mathrm{meV}$ are determined from Fig. 1. The ordering parameter $\eta=0.38 \pm 0.04$ is obtained with the aid of equation (3) in [9] and the derived $\Delta E_{B G R}$, while a comparable value of $\eta=0.36 \pm 0.05$ is obtained by considering the derived $\triangle E_{V B S}$.

The position of the $n$th extremum in the FKOs is [5] given by

$$
n \pi=\left\{\frac{4 \sqrt{2}}{3 q \hbar F}\left[\frac{m_{c}^{*} m_{h h}^{*}(001)}{m_{c}^{*}+m_{h h}^{*}(001)}\right]^{1 / 2}\left(E_{n}-E_{0}\right)^{3 / 2}\right\}+\chi
$$

where $E_{n}$ is the photon energy of the $n$th extremum, $E_{0}$ is the band gap, $F$ is the field, and $\%$ is an arbitrary phase factor, while $m_{c}^{*}$ and $m_{h h}^{*}(001)$ arc the effective mass of the electron and heavy hole [along (001)], respectively, in units of the free-electron mass. The relevant electron $\left(m_{c}^{*}\right)$ and heavy hole effective masses $\left(m_{h h}^{*}(001)\right)$ are 0.067 and 0.34 , respectively, for GaAs [12] and 0.118 and 0.66 ,

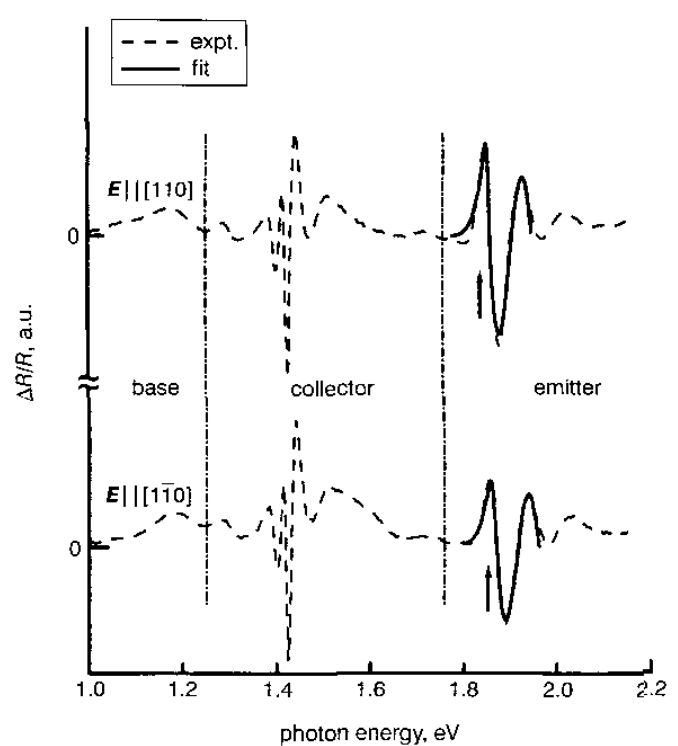

Fig. 1 Room temperature $P R$ spectra (dashed lines) for $N p N$ InGaP/InGaAsN/GaAs DHBT with light polarised E\|[1 10$]$ and $E \|\left[\begin{array}{lll}1 & 1 & 0]\end{array}\right.$

The solid lines are line-shape fits yiclding the energies as indicated by the arrows

respectively, for InGaP [13]. The FKOs indicate an electric field in the collector $F^{\text {coll }}=69 \pm 3 \mathrm{kV} / \mathrm{cm}$ and in the emitter $F^{\text {enit }}=155 \pm 5 \mathrm{kV} / \mathrm{cm}$.

For the linear, non-uniform field of a space-charge layer the FKOs are a measure of the maximum field [5]. We have performed a computer simulation of the field profiles using a comprehensive, self-consistent model [10] with the structure parameters mentioned above, including the effects of the light. Relevant quantities such as band offsets, effective masses, absorption coefficients and majority/minority carrier lifetimes in the different regions are discussed in [11]. The calculation yields $F^{c o l l}=72 \mathrm{kV} / \mathrm{cm}$ and $F^{e m i t}=180 \mathrm{kV} / \mathrm{cm}$.

The measured field in the collector region agreed well with the theoretical calculation, while the measured field in the emitter region is about $25 \mathrm{kV} / \mathrm{cm}$ smaller than that of the theoretical calculation. The difference between the experimental and theoretical values of the emitter field cannot be a result of doping variations of the sample since we used actual doping concentrations determined by polaron and Hall measurements for our calculation. Using a first-principles pseudopotential method, Froyen et al. [14] predict a strong, macroscopic, intrinsic electric field in ordered InGaP oriented along the ordering direction (i.e. along [ [ 1111 l] direction). Recently Huang et al. [15] reported an ordering-dependent properties study on four InGaP/GaAs HBT structures. For the same emitter doping level the emitter field in the more ordered materials $(\eta \approx 0.3)$ is about $20 \mathrm{kV} / \mathrm{cm}$ smaller than in the less ordered sample $(\eta \approx 0.1)$. The difference was ascribed to the influence of the piezoelectric field related to ordering. By including the possible ordering-induced partial screening effect, a reduction of $F^{\text {pieso }}$ from the theoretical calculation, which did not consider the influence of ordering, will give good agreement between experimental and theoretical values for the built-in ficld.

The dashed lines in Fig. 2 show the $300 \mathrm{~K} \mathrm{PR}$ and normalised first derivative surface photovoltage (SPV) spectra of the InGaP/InGaAsN/GaAs DHBT sample in the 


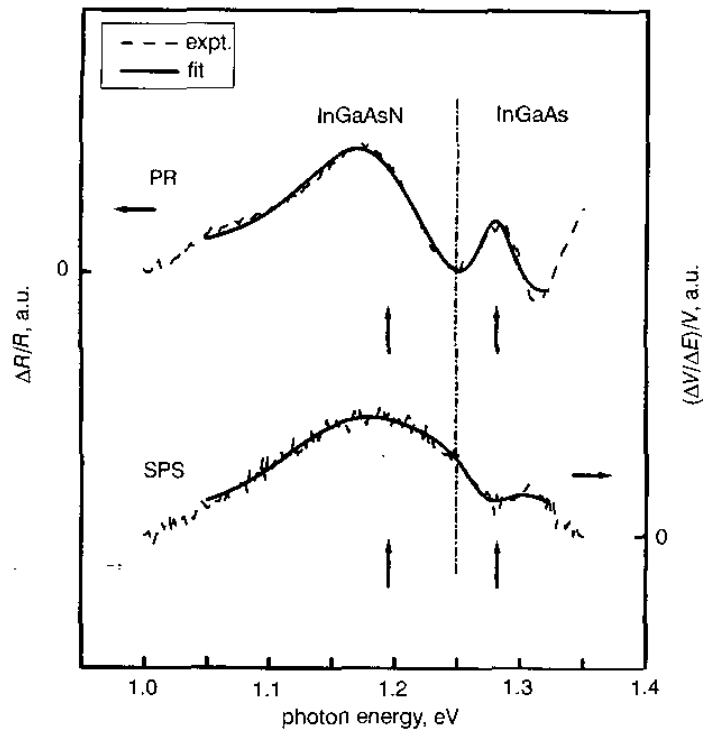

Fig. 2 Room temperature $P R$ and the normalised first derivative $S P V$ spectra of NpN InGaP/InGaAsN/GaAs DHBT sample in the region between 1.0 and $1.35 \mathrm{eV}$

The solid lines are line-shape fits yielding the energies as indicated by arrows

region between 1.0 and $1.35 \mathrm{eV}$. The features in this region are attributed to interband transitions originating from the InGaAs grading layers located between collector and base, and p-base InGaAsN. The line shape fits (the solid lines in Fig. 2) yield transition energies equal to $1.281 \pm 0.003$ and $1.196 \pm 0.003 \mathrm{eV}$ indicated by arrows. The feature around $1.28 \mathrm{eV}$ is attributed to the interband transitions of InGaAs grading layer with an average indium composition of $\sim 0.1$. The broad structure at $1.196 \mathrm{eV}$ is attributed to the direct transition at the band edge of $p$-base $\operatorname{In}_{x} \mathrm{Ga}_{1-x} \mathrm{As}_{1-y} \mathrm{~N}_{3}$. The In composition $x$ of 0.03 was determined by SIMS. The nitrogen composition $y=0.014$ is estimated using the phenomenological relationship shown in $[16]$, i.e. $E_{\mathrm{g}}\left(\ln _{0.03} \mathrm{Ga}_{0.97} \mathrm{As}_{1-y} \mathrm{~N}_{y}\right)=E_{\mathrm{g}}\left(\operatorname{In}_{0.03} \mathrm{Ga}_{0.97} \mathrm{As}\right)-12.4 \mathrm{yeV}$. The estimated $\mathrm{N}$ composition of 0.014 is slightly higher than the intended value of 0.01 . The broadening parameter of this feature is determined to be a rather large value of $\sim 120 \mathrm{meV}$. The large value of the broadening parameter might indicate the presence of defects with $\mathrm{N}$ incorporation into $\mathrm{In}_{0.03} \mathrm{Ga}_{0.97}$ As alloys and/or heavy doping of the material. The ability to observe a PR signal from the base region is in contrast to earlier observations made in [7], in which PR/CER yields information only about the properties of the collector and emitter, and does not produce any information about the base, because these methods cannot modulate highly doped layers. The reason that we are able to observe the PR feature from the base region might be due to a relatively lower doping concentration in the base region of the DHBT structure $\left(1 \times 10^{19} \mathrm{~cm}^{-3}\right)$ compared with the typical mid- $10^{19} \mathrm{~cm}^{-3}$ of base doping used in InGaP $/ \mathrm{GaAs}$ GaAs HBTs [11]. Higher base doping in InGaAsN-based DHBTs would further improve the characteristics of the device structure.

\section{Summary}

In summary, we have characterised an $\mathrm{NpN}$ InGaP/InGaAsN/GaAs DHBT structure using PR and SPS including dependence of the signals on polarisation. The ordering parameter is deduced from the polarisation dependence of InGaP emitter signals. It should be noted that while a band gap variation could be due to either ordering or lattice mismatch, polarisation-dependent splitting is the signature of ordering. From the observed FKOs we have evaluated $F^{\text {coll }}$ and $F^{\text {emit }}$. We have calculated these fields based on a comprehensive, self-consistent model, including the photovoltaic effect. There is good agreement for $F^{\text {coll }}$ between calculation and experiment. The difference in $F^{e m i t}$ is most likely due to ordering and its associated built-in piezoelectric field. The fits of PR and SPS signals from the p-base region yicld a band gap of InGaAsN with $E_{\mathrm{g}}(\mathrm{InGaAsN})=1.196 \mathrm{eV}$. The smaller $E_{\mathrm{g}}$ of InGaAsN has led to a lower $V_{\text {on }}$, which shows great potential for the application of InGaAsN in low-power electronics. An improvement of the quality with higher doping level of the InGaAsN base layer would further enhance the characteristics of the device structure.

\section{Acknowledgments}

The authors gratefully acknowledge the support of the National Science Council of the Republic of China and stimulating discussions with Professor Fred H. Pollak, Brooklyn College of the City University of New York.

\section{References}

1 SAKAI, S., UETA, Y., and TERAUCHI, Y.: 'Band gap energy and band lineup of III-V alloy semiconductors incotporating nitrogen and boron', Jpn. J. Appl. Phys. I, Regul. Pap. Short Notes, 1993, 32, pp. 4413-4417

2 LI, N.Y., HAINS, C.P. YANG, K., LU, J., CHENG, J., and LI, P.W. 'Organometallic vapor phase epitaxy growth and optical characteristics of almost $1.2 \mu \mathrm{m}$ GalnNAs three-quantam-well laser diodes:. Appl. Phys. Lett., 1999, 75, pp. 1051-1053

3 YANG, X., HEROUX, J.B., JURKOVIC, M.J., and WANG, W.I.: 'High performance $1.3 \mu \mathrm{m}$ InGaAsN: $\mathrm{Sb} / \mathrm{GaAs}$ quantum well lasers grown by molecular beam epitaxy', J. Vac. Sci. Technol. B, 2000, 18 . pp. 1484-1487

4 CHANG, PC. BACA, A.G., LI, N.Y., XIE, X.M., HOU, H.Q., and ARMOUR, E.: 'InGaP/InGaAsN/GaAs $N p N$ double-heterojunction bipolar transistor', Appl. Phys. Lett., 2000, 76, pp. 2262-2264

5 POLLAK, F.H., and SHEN, H.: 'Modulation spectroscopy of semiconductors: bulk/thin film, microstructures, surfaces/interfaces and devices', Mater: Sci. Eng. R Rep., 1993, 10, pp. 275-374

6 KRONIK, L., and SHAPIRA, Y.: 'Surface photovoltage phenomena: theory, experiment, and applications', Surf. Sci. Rep., 1999, 37, pp. 1-206

7 POLLAK, F.H.: 'Non-destructive, room temperature, characterization of wafer-sized III-V semiconductor device structures using contactless electromodulation and surface photovoltage spectroscopy', Proc SPIE-Int. Soc. Opt. Eng., 3944, pp. 408-422

8 MISHORI, B., LEIBOVITCH, M., SHAPIRA, Y., POLLAK, F.H., STREIT, D.C., and WOJTOWICZ, M.: 'Surface photovoltage spectroscopy of a GaAs/AlGaAs heterojunction bipolar transistor', Appl. Phys. Lett., 1998, 73, pp. 650-652

9 GREGER, E., GULDEN, K.H., MOSER, M. SCHMIEDEL, G., KIESEL, P, and DÖHLER, G.H.: 'Polarization anisotropy in the electroabsorption of ordered GaInP', Appl. Phys. Lett., 1997, 70, pp. 1459-1461

10 Silvaco Data Systems; Santa Clara, CA

11 HUANG, YS SUN, WD. POLLAK, F.H. FREEOUF, J.L., CALDER, I.D., and MALLARD, R.E.: 'Contactless electroreflectance characterization of GaInP/GaAs heterojunction bipolar transistor structures', Appl. Phys. Lett. 1998, 73, pp. 214-2i6

12 MADELUNG, O., and SCHULZ, M. (Eds.): 'Numerical data functional relationships in science and technology'. Landolt-Bornstein New Series, Group III (Springer, New York, 1987), Vol. 22a

13 JELEN, C., SLIVKEN, S. HE, X.G., RAZEGHI, $M$, and SHASTRY, S.: "Characterization of high quality GaInP/GaAs super-
lattices growr on GaAs and $\mathrm{Si}$ substrates by gas source molecular beam epitaxy, J. Vac. Sci. Technol. B, 1994, 12, pp. 1113-1115

14 FROYEN, S., ZUNGER, A., and MASCARENHAS, A.: 'Polarization fields and band offsets in GaInP/GaAs and ordered/disordered GaInP superlattices', Appl. Phys. Lett., 1996, 68, pp. 2852-2854

15 HUANG, YS SUN, WD POLLAK FH FREEOUF JL, CALDER, I.D., and MALLARD, R.E.: 'Properties of GaInP/GaAs heterojunction bipolar transistor structures: influence of GalnP ordering', in GERSHONI, D. (Ed.): 'Proceedings of the 24th International Conference on the Physics of semiconductors', Jerusalem, Israel, 1998 (World Scientific, Singapore), pp. 1247-1250

16 FAN, W.J., and YOON, S.F.: 'Electronic band structures of GalnNAs/GaAs compressive strained quantum wells', J. Appl. Phys., 2001, 90, pp. 843-847 